\title{
CO-ORDINATE CHANGES IN COMPLEMENTATION, SUP- PRESSION AND ENZYME PHENOTYPES OF A PYR-3 MUTANT OF NEUROSPORA CRASSA
}

\author{
VAL W. WOODWARD \\ Biology Deportment, Rice University, Houston \\ and \\ ROWLAND H. DAVIS \\ Botany Department, The University of Michigan, Ann Arbor
}

\section{INTRODUCTION}

Received 6.vi.62

THE pyr-3 mutants of Neurospora crassa appear to be blocked in pyrimidine synthesis at or prior to the reaction catalysed by the enzyme aspartate transcarbamylase (ATC) (Suyama, Munkres and Woodward, 1959; Davis, I96o; Davis and Woodward, 1962). The reaction, which involves the coupling of carbamyl phosphate (CAP) and aspartate to yield ureidosuccinic acid (US), cannot be catalysed by extracts of 40 of the 50 pyr-3 mutants tested (Davis and Woodward, I962). However, the other ten mutants appear to have ATC activity which is quantitatively similar and, by kinetic criteria, qualitatively indistinguishable from that found in wild type (Davis, I96o; Davis and Woodward, I962). Genetic analyses of the pyr-3 mutants yield a highly reproducible map of the locus, within which the two kinds of mutant are scattered without definite grouping (Suyama, Munkres and Woodward, 1959; Davis and Woodward, 1962). This finding suggests that the pyr-3 locus is responsible for a single protein with two functions (the "two functions" refer to the synthesis of CAP from $\mathrm{CO}_{2}$ and $\mathrm{NH}_{3}$ and to the coupling of CAP and aspartic acid to yield US; however, the synthesis of $\mathrm{US}$ from $\mathrm{CO}_{2}$ and $\mathrm{NH}_{3}$ may be a one-step reaction catalysed by a single protein), only one of which, the ATC reaction, has been identified (Davis and Woodward, 1962).

The bifunctional nature of the locus is further indicated by complementation experiments (Woodward, I962; Davis and Woodward, 1962). Two distinctly different types of heterocaryon are formed by the pyr-3 mutants: the first type is rudimentary and the second is vigorous, the growth rate approximating that of wild-type. A complementation map based on both types of heterocaryon is complex and only casually related to the genetic map of the locus (Woodward, 1962), but if the rudimentary types and the non-complementing pairs are pooled, the complementation map is found to consist of two complementing groups and a large " non-complementing" class (Davis and Woodward, I962). One of the complementation groups consists of all mutants having ATC; the other group consists of a single 
ATC-less mutant, KS-43. The " non-complementing " class contains the rest of the ATC-less mutants. These results indicate that the non-complementing mutants are deficient in two functions, only one of which is missing in each of the other classes (Woodward, 1962 ; Davis and Woodward, I962).

It is probable that the other function (besides the ATC reaction) involved here is the synthesis of CAP (Davis, I96o; Davis and Woodward, 1962; Davis, 1962a). This is suggested by the fact that a non-allelic mutation, $s$, which reduces ornithine transcarbamylase (OTC) activity to less than five per cent. of normal, leads to an elimination of the pyrimidine requirement (suppression) of the pyr-3 mutants having ATC (Davis, 1961; Davis, I962a; Davis, 1962b). Since the OTC reaction utilises CAP for arginine synthesis, a reduction of OTC activity of this magnitude probably reverses a deficiency in the production of a pyrimidine-specific CAP in such mutants. That there may be a pyrimidine-specific source of this compound is consistent with the view that its synthesis is normally tied directly to its utilisation, on the same protein, via the ATC reaction (Davis and Woodward, 1962).

The notion of a bifunctional protein remains to be proven directly; however, the following evidence is further indirect support for the hypothesis. It concerns the conversion of a non-complementing, ATC-less pyr-3 mutant which is not suppressible by $s$, to a complementing form containing ATC, and suppressible by the $s$ gene, all as a result of an "ultraviolet induced" mutation.

\section{EXPERIMENTAL}

The strains of Neurospora crassa used were KS-23, KS-43, col-4, al-2, 3730 r (pyr-3a), and the wild type 73a. KS-23 is a pyr-3 mutant characterised by its lack of ATC activity (Davis and Woodward, 1962), its inability to complement KS-43 (Woodward, 1962; Davis and Woodward, I962), its reverse mutation rate (Suyama, Munkres and Woodward, 1959), the yield of prototrophs when mated to other pyr-3 mutants (Suyama, et al., 1959) and by its unsuppressibility by the $s$ gene (Davis and Woodward, I 962). It is located near the distal end of the pyr-3 gene (Suyama et al., I959). KS-43 is the ATC-less mutant able to complement all mutants having ATC; it is unsuppressible by the $s$ gene and it is located at the proximal end of the pyr-3 gene. The other mutants of the pyr-3 series have been described previously (Suyama, Munkres and Woodward, I959; Woodward, 1962; Davis and Woodward, 1962).

To select mutations affecting the ability of KS-23 to complement $\mathrm{KS}-43$, the double mutants, KS-23 col-4 and KS-43 al-2, were constructed. Conidia of $\mathrm{KS}-23$ col-4 were irradiated with an LD-5o dose of ultraviolet light and overplated onto conidia of KS-43 al-2 on minimal agar medium containing 0.75 per cent. sorbose. Heterocaryons containing complementing $\mathrm{KS}-23$ and KS-43 nuclei were 
identified by their wild-type morphology, and from these, col-4 and al-2 homocaryons were recovered. The KS-23 col-4 strains retrieved by this procedure were retested for their ability to complement $\mathrm{KS}-43$, and when complementation was observed, the following tests were made: the altered KS-23 strains were back-crossed to the original, unirradiated KS-23 strain; they were crossed to KS-I 7 and KS-I 25 (mutants of the pyr-3 gene lying on either side of the KS-23 site); they were crossed to wild type; the spontaneous and ultraviolet induced reverse mutation rates were measured; they were tested for ATC activity (Davis, 1960; Davis and Woodward, 1962) and for their suppressibility by the $s$ gene (Davis and Woodward, 1962).

\section{RESULTS AND DISCUSSION}

Approximately 25 heterocaryons between irradiated KS-23 and $\mathrm{KS}-43$ were isolated. Since the homocaryotic KS-23 mutants recovered from the heterocaryons were alike in their ability to complement KS-43, reverse mutation rate, yield of prototrophs with closely linked mutants and suppressibility by $s$, only five $\left(\mathrm{b}_{2} \mathrm{C}_{7}, \mathrm{~b}_{2} \mathrm{C}_{3}\right.$, etc. $)$ were kept for detailed analysis. Table I shows the specific activity of ATC in acetone powder extracts of these 5 strains along with that of pyr-za

TABLE I

$A T C$ activity of five independently isolated, altered $K S-23$ strains, pyr-3a and $K S-48$

\begin{tabular}{|c|c|c|}
\hline Mutant & S.A. of ATC & Grown on \\
\hline $\begin{array}{l}\mathrm{b}_{2} \mathrm{C}_{1} \\
\mathrm{~b}_{2} \mathrm{C}_{3} \\
\mathrm{~b}_{2} \mathrm{C}_{4} \\
\mathrm{~b}_{2} \mathrm{C}_{6} \\
\mathrm{~b}_{2} \mathrm{C}_{7} \\
p y y-3 \mathrm{a} \\
\mathrm{KS}-48\end{array}$ & $\begin{array}{l}2 \cdot 34 \\
1 \cdot 51 \\
2 \cdot 05 \\
2 \cdot 56 \\
0 \cdot 86 \\
3-8 \\
2 \cdot 6\end{array}$ & $\begin{array}{ll}5^{\circ} \mu \mathrm{g} & \mathrm{UD} / \mathrm{ml} \\
5^{\circ} & , \\
50 & , \\
50 & , \\
50 & , \\
50 & , \\
50 & ,\end{array}$ \\
\hline
\end{tabular}

and KS-48 for comparison. The latter mutants are representative of the class of mutants possessing ATC (Davis and Woodward, 1962).

Strain $b_{2} C_{7}$ was crossed to the wild-type, $73 \mathrm{a}$, and from the cross the pyrimidine requiring progeny (X-1, X-2, etc.) were tested for complementation with $\mathrm{KS}-43$. Nearly 2000 pyrimidine requiring progeny from this cross were able to complement with $\mathrm{KS}-43$, and 20 have been shown to possess in vitro ATC activity equivalent to wild-type. A sample of these is shown in table 2. Fourteen of the progeny were then crossed to the suppressor mutant, $s$, and all 14 were found to be suppressible (table 3 ).

From these data, it can be seen that the altered strains derived from irradiated $\mathrm{KS}-23 \mathrm{col}-4$ conidia and the pyrimidine requiring progeny of crosses of one of these to wild-type are uniform in respect to complementation with KS-43, ATC activity and suppressibility by $s$. 
It has been reported (Woodward, 1962) that the reverse mutation rates of several of these strains are identical to the original KS-23 mutant and that the frequency of prototrophs recovered from crosses between these mutants and closely linked, pyr-3 mutants, i.e., KS-I 7 and KS-125, is the same as with the original KS-23 mutant.

TABLE 2

$A T C$ activity of several progeny from crosses between altered $K S-23$ strains and wild-type

\begin{tabular}{|c|c|c|}
\hline Strain & S.A. of ATC & Grown on \\
\hline $\begin{array}{l}X-1 \\
X-2 \\
X-3 \\
X-4 \\
X-16\end{array}$ & $\begin{array}{l}2 \cdot 82 \\
2 \cdot 02 \\
2 \cdot 90 \\
1 \cdot 02 \\
2 \cdot 17\end{array}$ & $\begin{array}{ll}50 & \mu \mathrm{g} \\
\mathrm{UD} / \mathrm{ml}\end{array}$ \\
\hline
\end{tabular}

TABLE 3

Crosses between s and altered KS-23 mutants yield progeny all of which are suppressible by $\mathrm{s}$

\begin{tabular}{|c|c|c|c|c|c|c|}
\hline Cross & & $\begin{array}{l}\text { No. and per cent. } \\
\text { pyr- progeny }\end{array}$ & $\begin{array}{l}\text { No growth } \\
\text { on min }\end{array}$ & OTC & $\begin{array}{l}\text { growth } \\
\text { on min }\end{array}$ & OTC \\
\hline $\begin{array}{l}X-2(5) \times s \\
X-2(2) \times s \\
X-2(6) \times s \\
X-6(18) \times s \\
X-6(19) \times s \\
X-6(21) \times s \\
X-6(8) \times s \\
X-23(3) \times s \\
X-23(5) \times s \\
X-23(6) \times s \\
X-23(7) \times s \\
X-23(11) \times s \\
X-23(10) \times s \\
X-1 \times s\end{array}$ & $\begin{array}{l}: \\
\dot{5} \\
\dot{5} \\
\dot{5} \\
\dot{5}\end{array}$ & $\begin{array}{c}8(36) \\
13(31) \\
24(44) \\
22(42) \\
29(55) \\
26(50) \\
28(47) \\
33(60) \\
20(34) \\
18(35) \\
22(76) \\
20(49) \\
22(39) \\
9(25)\end{array}$ & $\begin{array}{r}4 \\
6 \\
15 \\
11 \\
14 \\
9 \\
15 \\
12 \\
9 \\
9 \\
11 \\
9 \\
9 \\
6\end{array}$ & $\begin{array}{l}+ \\
+ \\
+ \\
+ \\
+ \\
+ \\
+ \\
+ \\
+ \\
+ \\
+ \\
+ \\
+ \\
+\end{array}$ & $\begin{array}{r}4 \\
7 \\
9 \\
11 \\
15 \\
17 \\
13 \\
21 \\
11 \\
9 \\
11 \\
11 \\
13 \\
3\end{array}$ & $\begin{array}{l}-(\text { all tested }) \\
-(3 \text { tested }) \\
-(3 \text { tested }) \\
-(3 \text { tested }) \\
-(3 \text { tested }) \\
-(3 \text { tested }) \\
-(3 \text { tested }) \\
-(3 \text { tested }) \\
-(3 \text { tested }) \\
-(3 \text { tested }) \\
-(3 \text { tested }) \\
-(3 \text { tested }) \\
-(3 \text { tested })\end{array}$ \\
\hline
\end{tabular}

From the crosses between altered KS-23 and the original KS-23, more than $5 \times 10^{6}$ ascospores from each of 5 crosses failed to yield prototrophs. A sample of the pyrimidine requiring progeny from the cross showed a I : I segregation for the ability to complement KS-43. Actually of the 40 progeny tested, 23 were unable and 17 were able to complement KS-43.

The results presented show that KS-23, a non-complementing, ATC-less, $p y r-3$ mutant can be converted by mutation to a complementing type which possesses ATC. These alterations of phenotype may be due to mutation of a modifier within the pyr-3 gene, since, with one exception, all of the 2000 pyrimidine dependent progeny of the 
altered strain and wild-type are of the altered phenotype. The one exceptional isolate is presumptive evidence that the alteration is at a mutational site distinct from the original $\mathrm{KS}-23$ site. Inasmuch as KS-23, carrying a single mutation, can regain ATC activity in this way while retaining a pyrimidine requirement, the data can be most simply interpreted as evidence that the original mutant was deficient in two enzymatic functions. The results, therefore, support the interpretation of past work, summarised above, from which the bifunctional nature of the pyr-3 gene was originally inferred.

Acknowledgments.-This work was supported by Research Grant RG-8653 from the National Institutes of Health and by a grant from the National Science Foundation to V. W. Woodward, and by an Institutional Research Grant to the University of Michigan from the American Cancer Society and a Research Grant (G-18012) from the National Science Foundation to R. H. Davis.

\section{REFERENCES}

DAVIS, ROWLAND H. 1960. An enzymatic difference among pyr-3 mutants of Neurospora crassa. Proc. Nat. Acad. Sci., Wash., 46, 677-682.

DAVIS, ROWLAND H. I961. Suppressor of pyrimidine 3 mutants of Neurospora and its relation to arginine synthesis. Science, 134, 470-471.

DAVIS, ROWLAND H. 1962a. Consequences of a suppressor gene effective with pyrimidine and proline mutants of Neurospora. Genetics, 47, 351-360.

DAVIS, ROWLAND H. 1962 $b$. A mutant form of ornithine transcarbamylase found in a strain of Neurospora carrying a pyrimidine-proline suppressor gene. Arch. Biochem. Biophys, 97, 185-191.

DAVIS, ROWLAND H., AND WOODWARD, VAL W. Ig62. The relationship between gene suppression and aspartate transcarbamylase activity in pyr-3 mutants of Neurospora. Genetics, 47, 1075-1083.

SUYAma, Y., MUNKRES, K. D., AND WoOdWARd, v. w. 1959. Genetic analyses of the pyr-3 locus of Neurospora crassa: the bearing of recombination and gene conversion upon intra-allelic linearity. Genetica, 3o, 293-3 I I.

WOODWARD, val w, ig62. Complementation and recombination among pyr-3 heteroalleles of Neurospora crassa. Proc. Nat. Acad. Sci., Wash., 48, 348-356. 